\title{
CHINOOK IS WORLD CHECKERS CHAMPION!
}

\author{
J. Schaeffer ${ }^{1}$ \\ University of Alberta \\ Edmonton, Canada
}

The computer program CHINOOK is now the World Checkers $(8 \times 8$ draughts $)$ Champion. The defending champion, Dr. Marion Tinsley, resigned his World Championship match against CHINOOK after 6 games due to illness. CHINOOK then played a match against Don Lafferty and retained its title.

Although this is the first time a computer program has been declared a World Champion against human opponents, the CHINOOK team feels little satisfaction in achieving the goal. It is hoped that Dr. Tinsley makes a full recovery, and that a match with CHINOOK can be arranged in 1995.

\section{DEREK OLDBURY (1924-1994): AN OBITUARY}

\section{J. Schaeffer ${ }^{1}$}

University of Alberta

Edmonton, Canada

Derek Oldbury, a World Champion at checkers $(8 \times 8$ draughts), died July 9, 1994. A keen games and computer games enthusiast, Derek was an avid reader of the ICCA Journal, and contributed several letters which appeared in these pages. In his sixties, Derek taught himself computer programming, and wrote a checkers program. His interest in computing led to the creation of his electronic games magazine Alpha-Beta, a quarterly publication containing articles, source code and binaries for a variety of games, including chess. His parting is greatly regretted by all who knew him.

\section{DEREK OLDBURY: A EULOGY}

\author{
A. Millett $^{2}$ \\ PC Solutions \\ Bournemouth, England
}

I first met Derek Oldbury at the 1989 Computer Olympiad, where each of us had entered our computer draughts programs. I already knew him by reputation through his famous MOVE-OVER book, and I had tried to use some of the ideas he had put forward in the early SAGE program I was entering in that tournament. What was striking about Derek's work was his attempt at a scientific analysis of the game, into parameters that could be used in a computer program - virtually the only attempt at this in the pre-computer age. Anyway, on meeting him, I found the intelligent and likable man lived up to the legend, and I struck up a friendship that we continued in subsequent years through correspondence and many telephone calls. The 1989 Olympiad saw most of the people who are active to this day in computer draughts - Gil Dodgen with his first program on the Apple Mac, Jonathan Schaeffer with his first version of CHINOOK, Derek Oldbury with his HUSTLER program just ported from the Apple-II to a 386 SX-16 PC, and myself with my early

\footnotetext{
1 University of Alberta, Department of Computing Science, Edmonton, Alberta T6G 2H1, Canada. E-mail: jonathan@cs.ualberta.cs

2 PC Solutions, P.O. Box 954, Bournemouth, BH 7 6YJ, England.
} 